\title{
Erratum to: The Impact of Supervision Training on Genetic Counselor Supervisory Identity Development
}

\author{
Carrie L. Atzinger • Kimberly Lewis • Lisa J. Martin • \\ Geoffrey Yager • Catherine Ramstetter • Katie Wusik
}

Published online: 31 August 2014

(C) National Society of Genetic Counselors, Inc. 2014

Erratum to: J Genet Counsel

DOI 10.1007/s10897-014-9730-7

\begin{abstract}
After the acceptance and publication of the above paper, the authors identified an error had been made in the calculation of the original PSDS scores. One of the 18 items on the PSDS was accidently duplicated and one item was missing in the original survey. Once this error was recognized, the PSDS scores were recalculated based on the 17 unique questions and analyses were redone. To determine the impact of the duplicated question, we created a scaled PSDS score (PSDS*18/17). The resulting scaled mean PSDS score (96.8, Range $=63-119, \mathrm{SD}=10.45$ ) was nearly identical to the mean PSDS score reported. Importantly, there were no changes in the relationships between PSDS score, training, supervisory experience, and clinical experience. Since all items on the PSDS are similarly weighted, there is no reason to believe the missing item would bias the results in any way. Therefore, despite the missing item, the study conclusions are unchanged.
\end{abstract}

The online version of the original article can be found at http://dx.doi.org/ 10.1007/s10897-014-9730-7.

C. L. Atzinger $(\bowtie) \cdot K$. Lewis $\cdot$ L. J. Martin $\cdot$ K. Wusik

Division of Human Genetics, Cincinnati Children's Hospital Medical

Center, 3333 Burnet Ave., ML 4006, Cincinnati, OH 45229, USA

e-mail: carrie.atzinger@cchmc.org

C. L. Atzinger $\cdot \mathrm{K}$. Lewis

College of Medicine, University of Cincinnati, Cincinnati, OH, USA

G. Yager · C. Ramstetter

College of Education, Criminal Justice, and Human Services,

University of Cincinnati, Cincinnati, OH, USA 